\title{
EVOLUÇÃO DE ESPODOSSOLO FERROCÁRBICO EM GLEISSOLO HÁPLICO NO PLANALTO DA SERRA DO MAR, RIO GUARATUBA (SP) $)^{(1)}$
}

\author{
M. ROSSI (2) \& J . P. QUEIROZ NETO(3)
}

\begin{abstract}
RESUMO
A bacia do Guaratuba situa-se no Parque Estadual da Serra do Mar com cabeceiras no Planalto Atlântico. Apresenta rochas gnáissicas em relevo de morros paralelos, declives acentuados e vegetação de Mata Atlântica, local mente de porte baixo, com clima tropical úmido e precipitação maior que $2.000 \mathrm{~mm}$ ano-1, sem estação seca. Há predomínio de Argissolos Vermelho-Amarelos (Podzólicos) e Cambissolos Háplicos (Cambissolos), com indícios de hidromorfismo. Nesse setor, em uma seqüência transversal à linha de mai or declive de uma vertente, estudouse uma associação Espodossolo Ferrocárbico hidromórfico típico álico (podzol hidromórfico) (E Sg) e Gleissolo Háplico Tb distrófico típico álico ou não (glei pouco húmico) (GXbd), assentada sobre seixos rolados e alteração do gnaisse, por meio de estudos detal hados em uma toposseqüência, definindo-se um sentido de evolução para esses solos. Os solos da área em posição elevada e paralela ao fundo do vale, bem como sua composi ção de sei xos e areias de quartzo/quartzito, levam a propor origem de deposição fluvial em antiga várzea, hoje suspensa como terraço. Nessa associação, ocorre uma transformação Espodossolo em Gleissolo, evidenciando que os solos desenvolveram-se dependentes de ambientes sucessivos, relacionados com a presença de vegetação florestal densa (matéria orgânica ácida) e de clima quente eúmido em um clima anterior, provavelmente com estação seca de início (formação do E Sg), seguido de clima atual sem estação seca (maior umidade-gleização, formação do GXbd), sendo pouco relacionados com modificações dos materiais originários (seixos e gnaisses).
\end{abstract}

Termos de indexação: pedologia, gênese, toposseqüência.

\footnotetext{
(1) Parte de Tese de Doutorado do primeiro autor, apresentada no 27 Congresso Brasileiro de Ciência do Solo em Brasília. Recebido para publicação em julho de 2000 e aprovado em dezembro de 2001.

(2) Pesquisador Científico do Instituto Agronômico - IAC. Caixa Postal 28, CEP 13001-970 Campinas (SP). Email: rossi @barao.iac.br

(3) Professor do Departamento de Geografia - FFLCH, Universidade de São Paulo - USP. Caixa Postal 2350, CEP 10600-970 São Paulo (SP). Email laboped@edu.usp.br
} 


\author{
SUMMARY: EVOLUTION OF ESPODOSOL FERROCARBIC TO HAPLIC \\ GLEISOL IN THE SERRA DO MAR PLATEAU, RIO \\ GUARATUBA, SÃO PAULO, BRAZIL
}

\begin{abstract}
The Guaratuba watershed is located at the "Parque Estadual da Serra do Mar" and has its headwaters in the Atlantic plateau. The area has a gneissic bedrock in a parallel hilly rel ief with high slopegradient, covered by the Atlantic forest consisting mostly of Iow sizetrees. The climateis humid tropical with rainfall of $2,000 \mathrm{~mm}$ year ${ }^{-1}$, with no dry season. Thepredominant soils are Red Yellow Argi sol (Typic Kandiudults or Pal eudults and Typic or Lithic Hapludults) and Haplic Cambisol (Typic Dystropepts or Typic Haplumbrepts) with redoximorphic features. In this area, in a right angletransverse by across the greatest slope gradient, the association of Ferrocarbic Espodosol (Arenic Haplaquods or Typic Haplorthods) and Haplic Gleisol (Typic Haplaquents) laid over gneiss-altered material was studied as well as pebbles of fluvial origin and sands. Thesoils' evol ution was also studied in detail al ong the topographic sequence. The soils of the area on a higher position and parallel to thebottom of theval ley bottom, and thequartzose composition of thepebbles and sands indicatea fluvial deposition origin from a former fluvial plain that occurs today as an el evated terrace These observations indicate that the soils were developed due to a succession of different environments, a dense forest vegetation (acid organic matter) and humid and hot climate, probably with dry season, in thebeginning (Arenic Haplaquods or Typic Haplorthods development) followed by one with no dry season (greater humidity, Typic Haplaquents development), less dependent on parent material (pebbles and sands, and gneiss).
\end{abstract}

Index terms: pedology, soil genesis, toposequence.

\section{NTRODUÇÃO}

A área deste estudo situa-se no Parque Estadual da Serra do Mar, que hoje se configura, do ponto de vista conservacionista, como a maior unidade de conservação do estado de São Paulo, e abrange em sua totalidade 309.948 ha. Representa importante remanescenteda flora efauna da região, caracterizada pela ocorrência da Mata Atlântica possuidora derica biodiversidade.

Encontra-se na Estação Biológica de Boracéia, originada da antiga Estação Experimental do Instituto Agronômico de Campinas, criada para o cultivo da Quina (utilizada no combate à malária). Hoje é administrada pelo Museu de Zoologia da Universidade de São Paulo (USP) e amparada pela Reserva Florestal de Casa Grande na proteção dos mananciais, administrada pela Companhia de Saneamento Básico doestadodeSãoPaulo(SABESP), que capta água para a cidade de SãoPaulo. Encontrase nos limites entre o litoral de Santos e de São Sebastião entre as coordenadas $45^{\circ} 47^{\prime} 43^{\prime \prime}$ e $45^{\circ} 55^{\prime} 56^{\prime \prime}$ de Longitude Oeste e $23^{\circ} 38^{\prime} 37^{\prime \prime}$ e $23^{\circ} 46^{\prime} 12^{\prime \prime}$ de Latitude Sul (Figura 1).

A bacia do Guaratuba insere-se na província geomorfológica do Planal toAtlântico eabrange parte do complexo cristalino, composto, sobretudo, por rochas granito-gnáissicas, em relevo de morros paralel os com planícies fluviais restritas. Apresenta- se revestida por formações superficiais pouco espessas de Argissolo Vermelho-Amarelo e Cambissol o Háplico, recobertas pel a floresta tropical (Mata Atlântica), com clima tropical úmido e precipitação $>2.000 \mathrm{~mm}^{2} \mathrm{ano}^{-1}$, sem estação seca (Rossi, 1999).

Nessa área, foi encontrada uma configuração topográfica que pode corresponder a um terraço fluvial, que se destaca na paisagem e revela uma seqüência onde se acham associados E spodossol os e Gleissolos, com características nítidas de

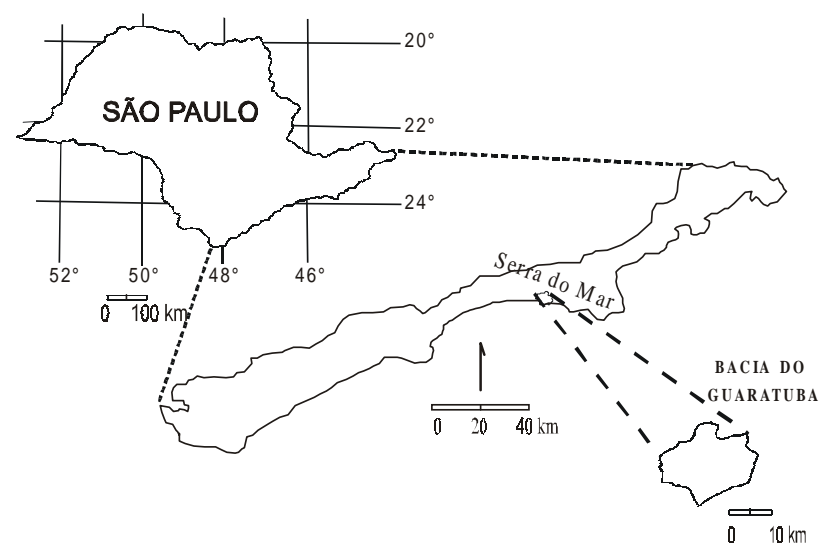

Figura 1. Mapa de localização da área de estudo. 
transformação pedológica (Rossi, 1999). Dessa forma, pelo estudo dessa seqüência, procurou-se identificar e definir os processos de evolução desses solos.

\section{MATERIAL E MÉTODOS}

A toposseqüência estudada situa-se em pequeno patamar do terço inferior de uma vertente talvez correspondendo a um terraço fluvial assentado sobre o embasamento rochoso alterado (Figura 2). Essa área está situada no sistema demorros paral el os do planalto do Guaratuba, apresentando uma associação de Espodossolo Ferrocárbico hidromórfico típico álico (podzol hidromórfico) (ESg) e Gleissolo Háplico Tb distrófico típico álico ou não (glei pouco húmico) (GXbd).

O procedimento empregado inspirou-se na proposta da análise estrutural da cobertura pedológica (Boulet et al., 1982a,b,c; Boulet, 1988) que propõe a observação detal hada dos perfis de sol o ao longo de uma toposseqüência. Para tanto, estabel eceu-sea toposseqüência acompanhando um barranco de estrada de mais de $600 \mathrm{~m}$ de comprimento, reavivado na ocasião. O levantamento topográfico foi realizado com emprego de topofil, trena e clinômetro, obtendo-se a base para a pl otagem das descrições morfológicas dos sol os e para a reprodução da organização da cobertura pedológica atingindo sempre o horizonte $\mathrm{Cr}$, descrevendo detalhadamente os horizontes pedológicos e definindo suas transições.

Prospecções suplementares com trado foram efetuadas para identificar a continuidade dos atributos perpendicularmente à toposseqüência. Foram descritos 38 perfis que incluem E spodossolos e Gleissolos, sendo apresentados na figura 3 os mais representativos da cobertura pedológica estudada. Os perfisT3.28 e 28A, eT3.35 e 35A foram escol hidos para mostrar as transformações e a passagem do Espodossolo em Gleissolo, que se observa também nos perfis indicados na figura 3.

Nesses pontos de prospecção (F igura 3), col etaramse as amostras de solo das diferentes camadas ou horizontes para análise laboratorial (físicas e químicas). Assim, construiu-se o perfil topográfico,

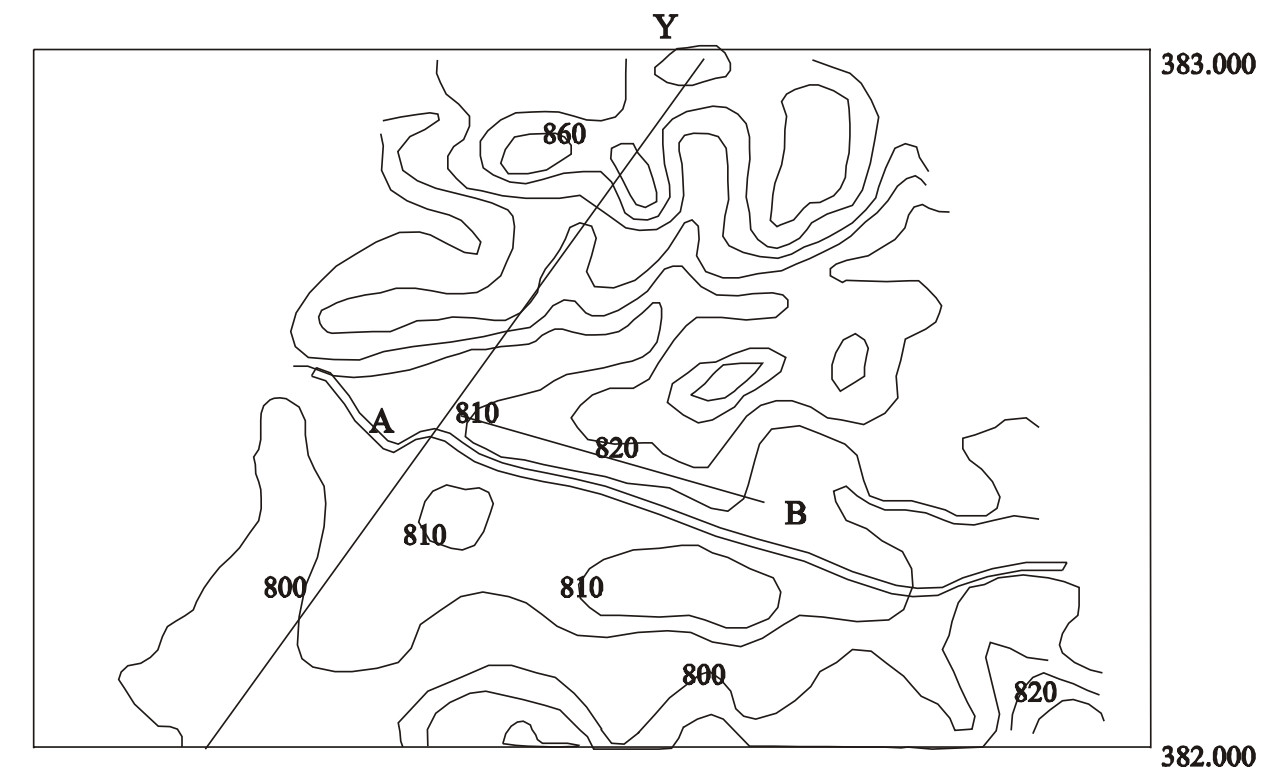

$407.000 \quad X$

$408.000 \mathrm{~km}$

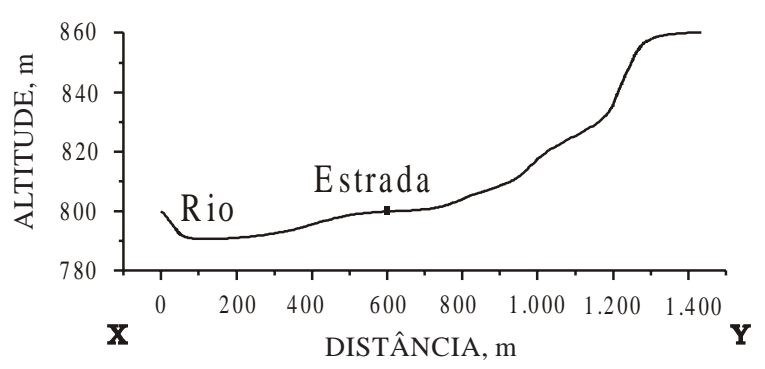

Figura 2. Representação do relevo local e localização da toposseqüência estudada. $X-Y=$ perfil representativo do relevo local; A - B =toposseqüência estudada. 
WNW

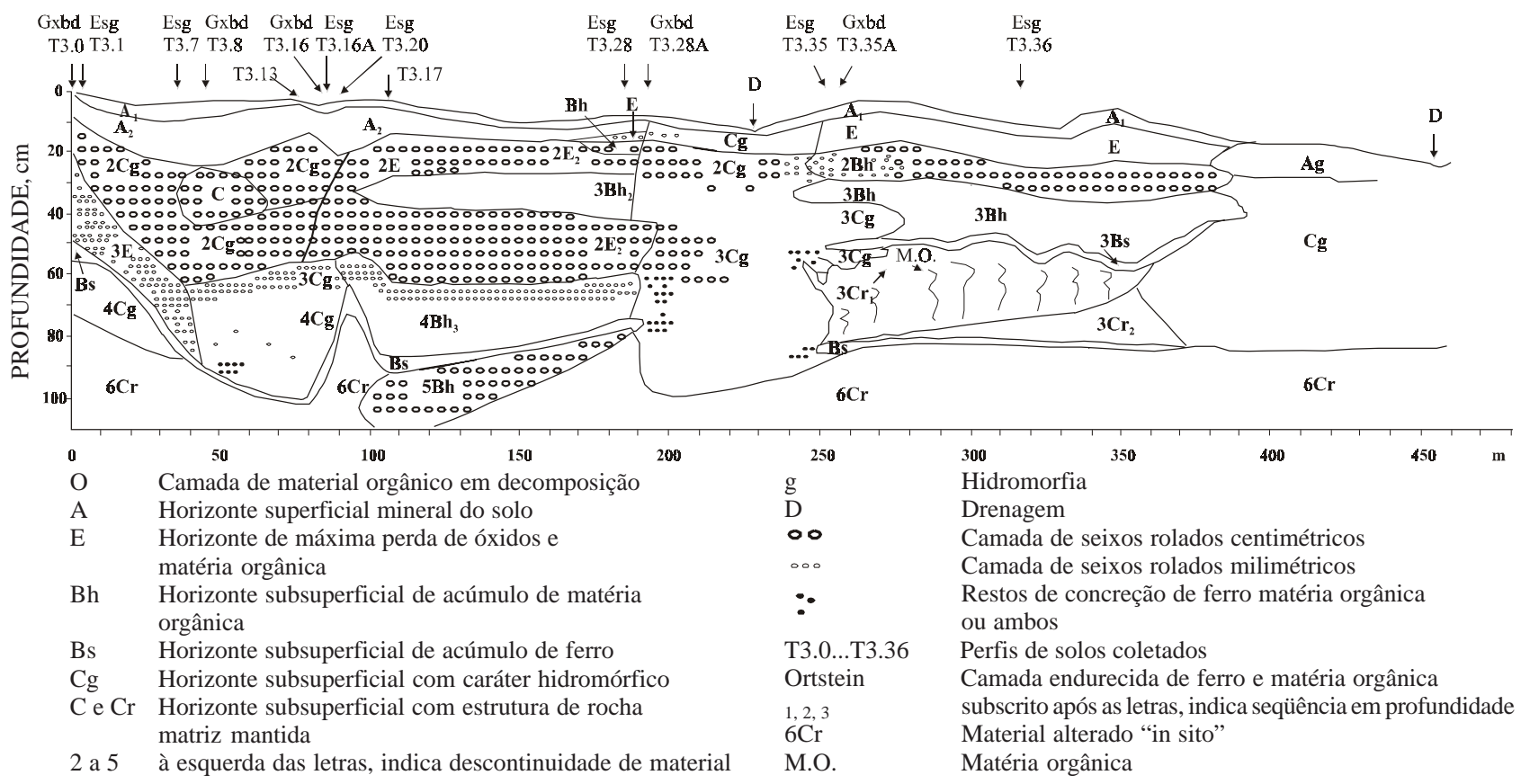

Figura 3. Representação reduzi da da toposseqüência mostrando os E spodossolos (E Sg) e Gleissolos (GXbd) da área de estudos. Na figura 4, estão representados em detalhe os perfis T3.28 e 28A, e T3.35 e 35A.

mostrando a distribuição dos solos, do relevo e da geologia da área que permitiu definir o sentido da evolução desses solos.

Nos perfis estudados, foram descritos os atributos morfológicos dos solos, de acordo com EMBRAPA (1979) e Lemos \& Santos (1996). Nas amostras coletadas, efetuaram-se análises físicas (granulometria: areias, silte e argila), químicas (cátions trocáveis $\mathrm{Ca}, \mathrm{Mg}, \mathrm{K}, \mathrm{Na}$; acidez extraível - $\mathrm{Al}, \mathrm{H}$; pH em água e $\mathrm{KCl}$; matéria orgânica e Fe total por ataque sulfúrico), utilizando-se como índices: Soma debases $(\mathrm{S})=\mathrm{Ca}+\mathrm{Mg}+\mathrm{K}+\mathrm{Na}$; Capacidade de troca catiônica $(\mathrm{T})=\mathrm{S}+\mathrm{Al}+\mathrm{H}$; Saturação por bases $(\mathrm{V} \%)$ $=100 \mathrm{~S} / \mathrm{T}$; Saturação por Al $(\mathrm{M} \%)=100 \mathrm{Al} /(\mathrm{S}+\mathrm{Al})$; Atividadedeargila $=\mathrm{T} \times 100 / \%$ argila, em queTa $>$ ou $=27 \mathrm{cmol}_{\mathrm{C}} \mathrm{kg}^{-1} \mathrm{eTb}<27 \mathrm{cmol}_{\mathrm{C}} \mathrm{kg}^{-1}$, conformeindicado por Camargo et al. (1986) e EMBRAPA (1999).

A identificação e a classificação das unidades de solos e de mapeamento seguiram a proposição do CNPS/EMBRAPA (Camargo et al., 1987; Oliveira et al., 1992), definindo os horizontes diagnósticos identificados no campoelaboratórioe, posteriormente, ajustados para o sistema brasileiro de classificação de sol os (EMBRAPA, 1999).

\section{RESULTADOS E DISCUSSÃO}

A toposseqüência apresenta sucessi vas passagens de Espodossolo Ferrocárbico hidromórfico típicoálico (podzol) para Gleissolo Háplico Tb distrófico típico álico ou não (glei pouco húmico) (Figura 3) com transição abrupta, porém progressiva ou interdigitada em curta distância. Esses solos desenvolvemse sobre uma sobreposição de diferentes materiais, inicialmente areias com matéria orgânica, sobre camadas descontínuas de seixos rolados de diversos diâmetros, assentadas sobre material fino siltoso e micáceo de alteração do gnaisse, por vezes interpenetrado por matéria orgânica e ferro. Essa seqüência ocorre sob vegetação de mata, com indivíduos arbóreo-arbustivos de porte baixo a médio.

A figura 3 mostra o horizonte superficial $A$ comum a toda a seqüência; abaixo deste, um nível de seixos em quase toda a extensão estudada de WNW, após espessar-se, bifurca-se atéatingir a parte central. Logo abaixo, observa-se outro nível, mais estreitoe deseixos menores. Outra camada de seixos aparece como uma lente isolada na parte basal dos perfis. Essas camadas de seixos aparentemente correspondem a um terraço fluvial (planície suspensa), que sofreu processo de deposição de baixa sel eção (areia grossa, cascalho fino e grosso). Em sua base, aparece a rocha alterada de estrutura conservada $(\mathrm{Cr})$, material fino siltoso com minerais primários (mica e fel dspato). Sobre esses materiais, sem respeitar seus limites, sucedem-selateral mente perfis de Espodossol os (ESg) e Gleissol os (GXbd). O horizonte superficial mineral A é comum a ambos, podendoser recoberto por um horizonte $\mathrm{O}$ dematéria orgânica. Abaixo do horizonte A e acima do Cr, 
alternam-se, lateralmente, sucessão de seqüências verticais de horizontes $\mathrm{E} / \mathrm{Bh} / \mathrm{Bs} / \mathrm{Cg}$ dos Espodossolos e Cg dos Gleissolos (Figura 4).

Em superfície, os dados analíticos (granulometria e química) são muito similares. Os horizontes subsuperficiais dos Espodossolos e dos Gleissolos mostram dados granulométricos muito semel hantes, indicando material fonte também similar. Os Espodossolos, por vezes, apresentam diversas camadas de acúmulo de matéria orgânica intercaladas por horizontes de iluviação E (como entre os perfis T3.20 eT3.28).

Os perfisT3.28 eT3.28A, em menos de dois metros, mostram a passagem lateral da sucessão vertical (A/E/2Bh/2E/3Bhs/3Bhs2/3Bsm) do Espodossolo (ESg), à esquerda, para a sucessão ( $\mathrm{A} / \mathrm{Cg} / 2 \mathrm{Cg} / 2 \mathrm{Cg} 2 /$ $2 \mathrm{Cg} 3 / 3 \mathrm{Cr}$ ) do Gleissolo (GXbd), à direita (Figura 4a).
O perfil deEspodossolo (T3.28) apresenta horizonte A superficial com $7 \mathrm{~cm}$ de espessura, cor pretobrunada (10YR 3/2), textura areia franca e estrutura fraca muito pequena a pequena granular, que passa a um horizonteA/E com $13 \mathrm{~cm}$, pouco mais daro, apesar de ainda escuro, bruno-acinzentado (10YR 4/2), de textura areia franca cascalhenta ( $40 \%$ de cascalho fino) esem estrutura (Figura 4a). Segueum horizonte 2Bh com matéria orgânica iluviada e $16 \mathrm{~cm}$ de espessura, bruno-escuro (10YR 3/3), detextura areia franca cascal henta (44 \% decascal ho grosso). Abaixo deste, formação de horizonte $2 \mathrm{E}$ com $23 \mathrm{~cm}$, brunoamarelado (10YR 5/3), também cascalhento em matriz arenosa e sobre outra concentração de matéria orgânica e ferro, formando um horizonte 3Bhs com 5 cm deespessura, bruno-vermelho-escuro (5YR 3/3), textura franco-arenosa sobre 3Bhs2 de $10 \mathrm{~cm}$ e cor bifásica bruno-vermelho-escura (5YR 3/4),

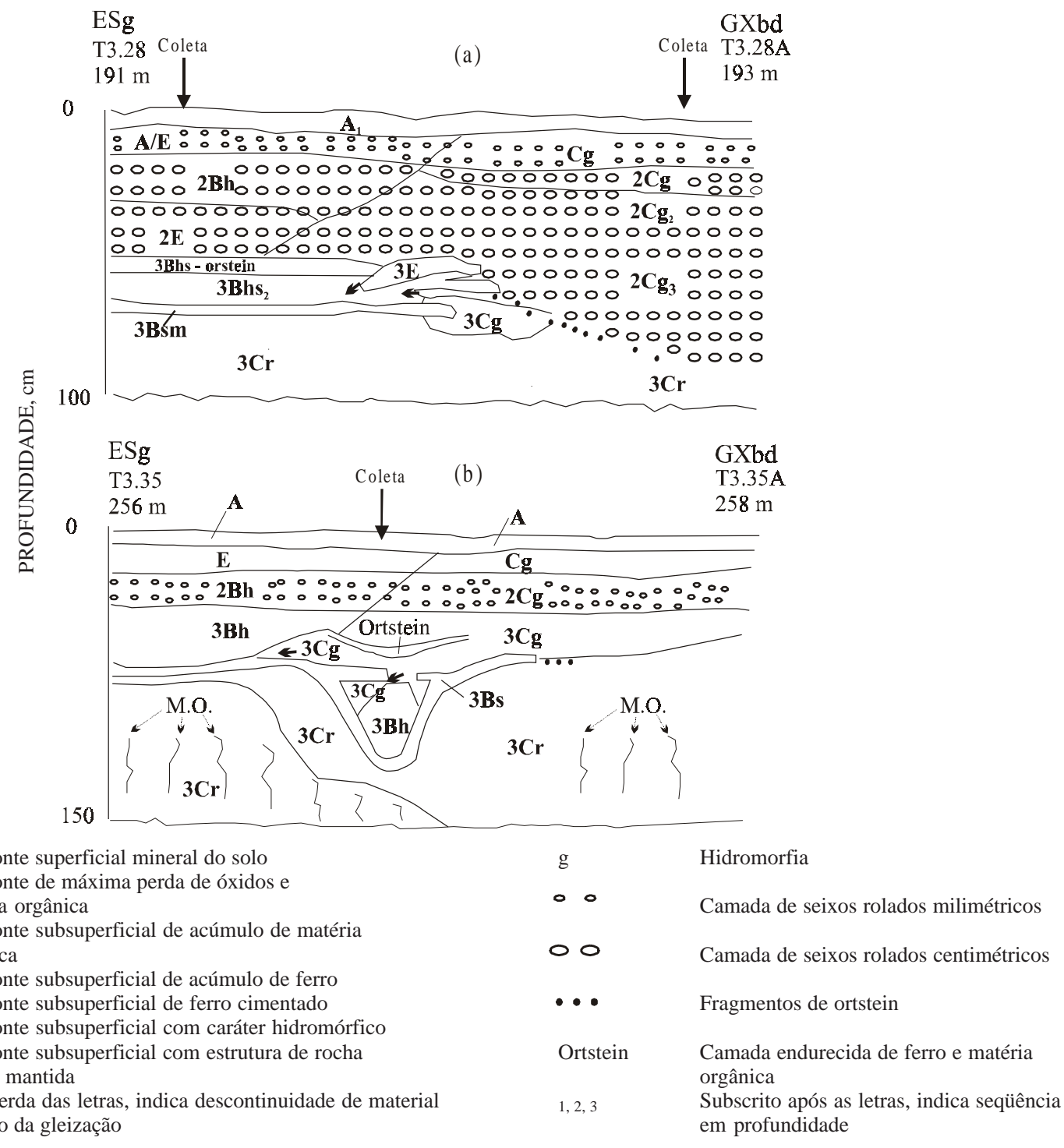

Figura 4. Perfis representando a passagem do solo Espodossolo para Gleissolo. (a) passagem abrupta T3.28 para T3.28A; (b) detalhes da transformação T3.35 e T3.35A. 
alternando em faixas com bruno-amarelado (10YR $6 / 8$ ) e um 3Bsm de $3 \mathrm{~cm}$ bruno-vermelho-escuro (2,5YR 3/2), rodeado por bruno (7,5YR 5/8) e brunoavermelhado (5YR 5/8) (endurecidos, ortstein), de textura franco-argilo-arenosa e estrutura maciça. Por fim, encontra-se o horizonte $3 \mathrm{Cr}$ com $29 \mathrm{~cm}$ de espessura, amarelo-claro (5Y 7/4), apresentando volumes mais claros e escuros de textura francoarenosa da alteração do gnaisse, mantendo a estrutura bandada da rocha.

O perfil T3.28A, dois metros adiante do T3.28 e desenvolvido sobre o material similar, apresenta horizonte superficial A com $10 \mathrm{~cm}$ de espessura, cinzento bruno-amarelado (10YR 4/2), de textura areia franca e estrutura fraca muito pequena a pequena granular, similar ao Espodossolo (podzol). Seguem-se diversos horizontes Cg, que variam pela presença de cascalho de diversos tamanhos e col oração. O Cg, com $20 \mathrm{~cm}$ de espessura, é brunoamarelado (10YR 5/3), apresenta textura francoarenosa cascalhenta ( $40 \%$ de cascalho fino) e estrutura maciça. Abaixo, segue horizonte $2 \mathrm{Cg}$ com $10 \mathrm{~cm}$, vermel ho-amarelado (10YR 6/3), de textura franco-arenosa cascal henta ( $43 \%$ de cascal ho grosso) e estrutura maciça, sobre horizonte $2 \mathrm{Cg} 2$ de $20 \mathrm{~cm}$ de espessura, col oração amarelo-acinzentado-escura $(2,5 Y 5 / 2)$, de textura franco-arenosa cascalhenta como o anterior e estrutura também maciça. A seguir, ocorre o $2 \mathrm{Cg} 3$, com $30 \mathrm{~cm}$ de espessura, mosqueado amarelo $(2,5 Y$ 6/3) com pequenos volumes mais pálidos cinzento-amarelados $(2,5 Y 7 /$ 2) e mais vivos, vermelho-amarelados (5YR 6/6), de textura franco-arenosa e estrutura maciça. Todos assentes sobre o mesmo horizonte $3 \mathrm{Cr}$ de alteração do gnaisse descrito no perfil T3.28, porém com algumas variações de cor, mosqueado cinza-claro (10Y 7/1 e 5Y 7/2).

O perfil T3.35 revel a as transformações ocorrentes na área, porém com nítida interpenetração de matéria orgânica no material alterado do gnaisse e apresentando caráter plácico (fino pan cimentado), principalmente de ferro (Figura 4b).

O perfil T3.35 mostra horizontesuperficial A com $15 \mathrm{~cm}$ de espessura, preto-brunado (10YR 3/1), de textura areia franca e estrutura fraca muito pequena a pequena granular. Segue horizonte $E$ com $12 \mathrm{~cm}$, bruno-acinzentado (10YR 4/2), de textura areia cascal henta ( $43 \%$ de cascal ho fino) e sem estrutura aparente. Abaixo, segue horizonte $2 \mathrm{Bh}$ lateralmente contínuo, com espessura de $8 \mathrm{~cm}$, bruno-escuro (10YR 3/3), detextura areia franca e sem estrutura aparente. Logo abaixo, de forma não-contínua, percebem-se resquícios de uma crosta de ferrojá na massa do horizonte gleizado $3 \mathrm{Cg}$ que apresenta $12 \mathrm{~cm}$ de espessura, com cor mosqueado-amarelada $(2,5 Y 7 / 3)$, bruno-amarelada (10YR 5/8) e brunoescura (10YR 3/4), de textura franco-arenosa e estrutura maciça. No meio dessa massa gleizada, aparece nova crosta de ferro, horizonte $3 B$ s com $3 \mathrm{~cm}$ de espessura, de cor mosqueada bruno-avermel hada (2,5YR 5/8), bruno-amarelada (10YR 6/6) e vermel ho-amarelada (7,5YR 6/8) de consistência ligeiramente dura, tendendo a macia.

Em forma de bolsa com $30 \mathrm{~cm}$, destaca-se outro horizonte de concentração de matéria orgânica 3Bh, intrincado na massa gleizada do horizonte $3 \mathrm{Cg}$, amarelo-acinzentado (2,5Y 6/2), mosqueadoamarelado (2,5Y 7/6) a bruno-amarelado (10Y R 6/8) e bruno-amarelado-escuro (10YR 4/3), de textura franco-arenosa. Aparentemente, é um testemunho do 3Bh acima que está sofrendo transformação pela hidromorfia remontante. Na base desta bolsa, ainda podem ser observados fragmentos de antiga crosta de ferro, que, aparentemente, apresentava 2 a $3 \mathrm{~cm}$ de espessura. Todo esse material está assente no horizonte $3 \mathrm{Cr}$ dealter ação do gnaisse comum a toda a toposseqüência estudada, aqui ocorrendo de forma irregular, com $58 \mathrm{~cm}$ de espessura na base da bolsa eaté $1 \mathrm{~m}$ nas outras porções do perfil. Está dividido conforme a interpenetração de matéria orgânica, principalmente no lado esquerdo do perfil, e apresenta cor variegada bruno-escura (10YR 3/3), bruno-amarelada (10Y R 6/6) e vermelho-amarelada (5YR 6/3) e textura franco-arenosa e estrutura bandada como da rocha.

Os dados analíticos da passagem Espodossolo/ Gleissolo dos perfis T3.28 e T3.28A (Quadro 2) mostram que os teores de argila dos horizontes do Espodossolo são mantidos na passagem para o Gleissolo (100-120 g kg-1), exceção ao material fino do 3Bhs e 3Bsm (187 e $179 \mathrm{~g} \mathrm{~kg}^{-1}$ ) que, lateralmente, passam ao $3 \mathrm{E}$ e $3 \mathrm{Cg}$ e, posteriormente, a $2 \mathrm{Cg} 2$ e $2 \mathrm{Cg} 3$ com 145 e $143 \mathrm{~g} \mathrm{~kg}^{-1}$. Essa diminuição do teor de argila é acompanhada pela do ferro total, que no 3Bhs2 é de 88,3 $\mathrm{g} \mathrm{kg}^{-1}$ e chega a $203 \mathrm{~g} \mathrm{~kg}^{-1}$ no 3Bsm, passando nos horizontes correspondentes do Gleissolo (2Cg3) a 16,3 $\mathrm{g} \mathrm{kg}^{-1}$.

Esse fato mostra que o aumento da hidromorfia provoca o rápido desaparecimento dos horizontes ferruginosos, sendo testemunhado por fragmentos de ortstein, em continuidade a esses níveis endurecidos, nointerior da massa gl eizada (Figura 4). Lateralmente, nos horizontes 3Bhs, 3Bhs 2 e 3Bsm, ocorre também declínio do carbono total em dir eção à gleização, $3 \mathrm{E}$ e $3 \mathrm{Cg}$. Os outros dados mostram-se homogêneos, com pH ácido e muito próximos (pH em $\mathrm{H}_{2} \mathrm{O}$ de 4,2 a 4,6); a soma de bases apresenta-se baixa, com teores inferiores a $1,0 \mathrm{cmol}_{\mathrm{C}} \mathrm{kg}^{-1}$ (valor $\mathrm{S}$ de 0,3 a $0,75 \mathrm{cmol}_{\mathrm{c}} \mathrm{kg}^{-1}$ ) e capacidade de troca também baixa. Os teores de ferro total podem ser expressivos nos horizontes de acumulação 3Bhs, 3Bhs2 e 3Bsm, do Espodossolo.

No Gleissolo, encontra-se al guma concentração desse el emento, no horizonte $2 \mathrm{Cg} 3$ e $3 \mathrm{Cr}$, em val ores e profundidades aproximadas aos do 3Bhs e 3Bsm, indicando certa permanência desseel emento apesar do avanço da hidromorfia, porém os valores são muito homogêneos para ambos (Fe de 1,5 a 7,5 g kg-1 exceção 
Quadro 1. Resultados analíticos dos perfis da pedotoposseqüência Espodossolo Ferrocárbico (ESg)/ Gleissolo Háplico (GXbd)

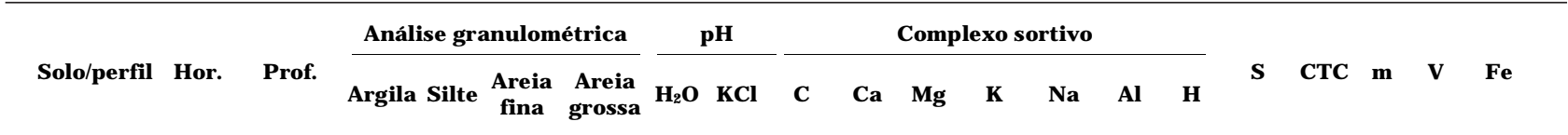

\begin{tabular}{|c|c|c|c|c|c|c|c|c|c|c|c|c|c|c|c|c|c|c|c|c|}
\hline \multirow[b]{2}{*}{ GXbd T3.0 } & \multirow[b]{2}{*}{ A1 } & \multirow{2}{*}{$\begin{array}{l}\mathrm{cm} \\
0-8\end{array}$} & \multicolumn{4}{|c|}{$\mathrm{g} \mathrm{kg}^{-1}$} & \multicolumn{3}{|c|}{$\mathrm{g} \mathrm{kg}^{1}$} & \multicolumn{8}{|c|}{$\mathrm{cmol}_{\mathrm{K} \mathrm{Kg}^{-1}}$} & \multicolumn{2}{|c|}{ - \% - } & $\mathrm{g} \mathrm{kg}^{-1}$ \\
\hline & & & 91 & 61 & 245 & 603 & 4,3 & 3,6 & 31 & 0,3 & 0,2 & 0,23 & 0,08 & 1,5 & 7,1 & 0,81 & 9,41 & 65 & 9 & 2,3 \\
\hline & $\mathrm{A} 2$ & $8-20$ & 108 & 69 & 178 & 645 & 4,3 & 3,7 & 7 & 0,2 & 0,2 & 0,07 & 0,03 & 0,6 & 2,6 & 0,50 & 3,70 & 55 & 14 & 3,1 \\
\hline & $\mathrm{Cg}$ & $20-30$ & 159 & 107 & 194 & 540 & 4,5 & 4,1 & 4 & 0,2 & 0,1 & 0,03 & 0,02 & 1,1 & 3,7 & 0,35 & 5,15 & 76 & 7 & 1,2 \\
\hline & crosta & $30-33$ & 172 & 167 & 218 & 443 & 4,5 & 4,2 & 3 & 0,1 & 0,1 & 0,02 & 0,03 & 1,0 & 4,3 & 0,25 & 5,55 & 80 & 5 & 2,3 \\
\hline & $2 \mathrm{Cg}$ & $33-75$ & 197 & 213 & 206 & 384 & 4,7 & 4,3 & 1 & 0,1 & 0,1 & 0,03 & 0,04 & 0,9 & 2,5 & 0,27 & 3,87 & 77 & 7 & 23,0 \\
\hline & $2 \mathrm{Cr}$ & $75-160$ & 178 & 208 & 221 & 393 & 4,7 & 4,3 & ND & 0,1 & 0,1 & 0,02 & 0,05 & 0,8 & 2,0 & 0,27 & 3,07 & 75 & 9 & 30,0 \\
\hline Sg T3.1 & A1 & $0-10$ & 115 & 122 & 229 & 534 & 4,3 & 3,7 & 19 & 0,3 & 0,2 & 0,13 & 0,10 & 1,4 & 5,6 & 0,73 & 7,73 & 66 & 9 & 1,6 \\
\hline & A2 & $10-23$ & 69 & 71 & 180 & 680 & 4,1 & 3,8 & 18 & 0,2 & 0,2 & 0,06 & 0,04 & 0,7 & 6,5 & 0,50 & 7,70 & 58 & 6 & 2,0 \\
\hline & $\mathrm{Bs}$ & $23-30$ & 171 & 139 & 204 & 486 & 4,4 & 4,1 & 4 & 0,3 & 0,2 & 0,04 & 0,03 & 1,0 & 3,6 & 0,57 & 5,17 & 64 & 11 & 79,0 \\
\hline & $2 \mathrm{E} 1$ & $30-36$ & 68 & 64 & 217 & 651 & 4,3 & 3,9 & 6 & 0,2 & 0,2 & 0,03 & 0,02 & 0,3 & 2,2 & 0,45 & 2,95 & 40 & 15 & 2,7 \\
\hline & $2 \mathrm{E} 2$ & $36-50$ & 60 & 53 & 209 & 678 & 4,4 & 4,1 & 1 & 0,2 & 0,2 & 0,03 & 0,01 & 0,1 & 1,5 & 0,44 & 2,04 & 19 & 22 & 2,3 \\
\hline & $2 \mathrm{Bh}$ & $50-55$ & 107 & 114 & 177 & 602 & 4,1 & 3,7 & 25 & 0,2 & 0,1 & 0,02 & 0,02 & 3,3 & 9,3 & 0,34 & 12,94 & 91 & 3 & 3,8 \\
\hline & $3 \mathrm{Cg}$ & $55-77$ & 181 & 159 & 233 & 427 & 4,4 & 4,1 & 6 & 0,2 & 0,2 & 0,02 & 0,03 & 1,6 & 5,8 & 0,45 & 7,85 & 78 & 6 & 2,2 \\
\hline & $3 \mathrm{Cr}$ & $77-120$ & 133 & 204 & 228 & 435 & 4,4 & 4,1 & 4 & 0,3 & 0,2 & 0,04 & 0,04 & 1,4 & 3,0 & 0,58 & 4,98 & 71 & 12 & 2,0 \\
\hline Esg T3.20 & A & $0-25$ & 54 & 67 & 177 & 702 & 4,4 & 3,9 & 10 & 0,3 & 0,2 & 0,04 & 0,05 & 0,8 & 3,5 & 0,59 & 4,89 & 58 & 12 & 5,4 \\
\hline & $\mathrm{Bh}$ & $25-35$ & 131 & 109 & 141 & 619 & 4,2 & 3,4 & 85 & 0,3 & 0,2 & 0,09 & 0,13 & 2,5 & 10,5 & 0,72 & 13,72 & 78 & 5 & 1,4 \\
\hline & $\mathrm{E}$ & $35-65$ & 56 & 35 & 184 & 725 & 4,5 & 4,0 & 2 & 0,2 & 0,1 & 0,02 & 0,02 & ND & 1,0 & 0,34 & 1,34 & 0 & 25 & 5,3 \\
\hline & $2 \mathrm{Bh}$ & $65-80$ & 107 & 48 & 249 & 596 & 4,2 & 3,8 & 13 & 0,2 & 0,2 & 0,02 & 0,02 & 2,0 & 7,6 & 0,44 & 10,04 & 82 & 4 & 1,1 \\
\hline & $2 \mathrm{Bh} 2$ & $80-90$ & 99 & 60 & 227 & 614 & 4,4 & 4,0 & 7 & 0,2 & 0,1 & 0,02 & 0,03 & 1,3 & 6,3 & 0,35 & 7,95 & 79 & 4 & 5,1 \\
\hline & $2 \mathrm{Bh} 3$ & $90-100$ & 87 & 62 & 89 & 762 & 4,4 & 3,9 & 5 & 0,2 & 0,2 & 0,03 & 0,05 & 1,4 & 6,0 & 0,48 & 7,88 & 74 & 6 & 1,7 \\
\hline & $3 \mathrm{Bs}$ & $100-135$ & 188 & 179 & 386 & 247 & 4,6 & 4,2 & 2 & 0,3 & 0,2 & 0,03 & 0,06 & 1,3 & 4,7 & 0,59 & 6,59 & 69 & 9 & 30,5 \\
\hline Esg T3.7 & A1 & $0-20$ & 109 & 60 & 235 & 596 & 4,6 & 4,0 & 11 & 0,6 & 0,3 & 0,09 & 0,09 & 0,6 & 3,4 & 1,08 & 5,08 & 36 & 21 & 24,1 \\
\hline & A2 & $20-58$ & 95 & 58 & 179 & 668 & 4,8 & 4,3 & 8 & 0,5 & 0,3 & 0,03 & 0,04 & 0,3 & 2,7 & 0,87 & 3,87 & 26 & 22 & 4,4 \\
\hline & Bhs1 & $58-80$ & 98 & 61 & 208 & 633 & 4,4 & 4,0 & 8 & 0,2 & 0,2 & 0,03 & 0,06 & 0,7 & 3,5 & 0,49 & 4,69 & 59 & 10 & 32,6 \\
\hline & Bhs2 & $80-83$ & 216 & 123 & 169 & 492 & 4,5 & 4,0 & 11 & 0,3 & 0,2 & 0,04 & 0,07 & 1,1 & 6,7 & 0,61 & 8,41 & 64 & 7 & 36,3 \\
\hline & $\mathrm{Cr}$ & $83-100$ & 183 & 108 & 326 & 383 & 4,5 & 4,0 & 1 & 0,2 & 0,2 & 0,02 & 0,05 & 0,9 & 1,7 & 0,47 & 3,07 & 66 & 15 & 2,7 \\
\hline GXbd T3.8 & Al & $0-4$ & 109 & 54 & 177 & 660 & 4,8 & 4,2 & 11 & 0,5 & 0,3 & 0,08 & 0,09 & 0,4 & 2,6 & 0,97 & 3,97 & 29 & 24 & 5,5 \\
\hline & $\mathrm{A} 2$ & $4-20$ & 110 & 62 & 170 & 658 & 4,6 & 4,2 & 7 & 0,2 & 0,2 & 0,05 & 0,05 & 0,5 & 2,3 & 0,50 & 3,30 & 50 & 15 & 7,5 \\
\hline & $\mathrm{C} 1$ & $20-40$ & 115 & 59 & 198 & 628 & 4,5 & 4,2 & 7 & 0,3 & 0,2 & 0,04 & 0,05 & 0,4 & 2,2 & 0,59 & 3,19 & 40 & 19 & 1,9 \\
\hline & $\mathrm{Cgl}$ & $40-60$ & 114 & 61 & 181 & 644 & 4,7 & 4,3 & 3 & 0,3 & 0,2 & 0,03 & 0,03 & 0,3 & 1,7 & 0,56 & 2,56 & 35 & 22 & 5,7 \\
\hline & $\mathrm{Cg} 2$ & $60-90$ & 139 & 79 & 145 & 637 & 4,4 & 4,1 & 1 & 0,2 & 0,1 & 0,02 & 0,04 & 0,6 & 1,9 & 0,36 & 2,86 & 63 & 13 & 35,4 \\
\hline & $\mathrm{Cr}$ & $90-100$ & 180 & 113 & 279 & 428 & 4,6 & 4,2 & ND & 0,2 & 0,1 & 0,04 & 0,09 & 1,1 & 1,3 & 0,43 & 2,83 & 72 & 15 & 8,2 \\
\hline GXbd T3.13 & Al & $0-10$ & 159 & 79 & 188 & 574 & 4,6 & 4,0 & 11 & 0,4 & 0,3 & 0,09 & 0,10 & 0,7 & 2,5 & 0,89 & 4,09 & 44 & 22 & 23,6 \\
\hline & $\mathrm{Cg} 1$ & $10-20$ & 162 & 88 & 196 & 554 & 4,6 & 4,2 & 7 & 0,3 & 0,3 & 0,05 & 0,08 & 0,4 & 2,2 & 0,73 & 3,33 & 35 & 22 & 2,3 \\
\hline & $\mathrm{Cg} 2$ & $20-40$ & 179 & 61 & 190 & 570 & 4,4 & 4,1 & 6 & 0,3 & 0,2 & 0,05 & 0,05 & 0,5 & 2,5 & 0,60 & 3,60 & 45 & 17 & 2,6 \\
\hline & $\mathrm{Cg} 3$ & $40-56$ & 165 & 91 & 199 & 545 & 4,5 & 4,1 & 2 & 0,2 & 0,2 & 0,03 & 0,04 & 0,5 & 1,5 & 0,47 & 2,47 & 52 & 19 & 24,4 \\
\hline & $\mathrm{Cg} 4$ & $56-80$ & 175 & 107 & 221 & 497 & 4,4 & 4,0 & 1 & 0,2 & 0,2 & 0,02 & 0,06 & 0,7 & 1,5 & 0,48 & 2,68 & 59 & 18 & 25,7 \\
\hline & $\mathrm{Cr}$ & $80-100$ & 198 & 130 & 289 & 383 & 4,8 & 4,2 & ND & 0,3 & 0,2 & 0,03 & 0,08 & 0,9 & 2,1 & 0,61 & 3,61 & 60 & 17 & 10,7 \\
\hline GXbdT 3.16 & A & $0-15$ & 126 & 66 & 196 & 612 & 4,6 & 4,1 & 13 & 0,4 & 0,2 & 0,06 & 0,06 & 0,8 & 3,8 & 0,72 & 5,32 & 53 & 14 & 5,5 \\
\hline & C & $15-30$ & 141 & 42 & 165 & 652 & 4,4 & 4,0 & 9 & 0,4 & 0,2 & 0,04 & 0,04 & 0,7 & 2,7 & 0,68 & 4,08 & 51 & 17 & 19,3 \\
\hline & $\mathrm{Cg}$ & $30-50$ & 192 & 45 & 219 & 544 & 4,4 & 4,1 & 3 & 0,3 & 0,2 & 0,02 & 0,03 & 0,9 & 2,7 & 0,55 & 4,15 & 62 & 13 & 19,5 \\
\hline & $\mathrm{Cr}$ & $50-80$ & 209 & 99 & 247 & 445 & 4,4 & 4,0 & 1 & 0,2 & 0,1 & 0,03 & 0,09 & 1,5 & 2,5 & 0,42 & 4,42 & 78 & 10 & 2,8 \\
\hline Esg T3.16A & Al & $0-10$ & 168 & 56 & 169 & 607 & 4,5 & 3,8 & 16 & 0,2 & 0,2 & 0,12 & 0,21 & 1,3 & 4,7 & 0,73 & 6,73 & 64 & 11 & 6,1 \\
\hline & Bs & $10-20$ & 197 & 49 & 165 & 589 & 4,5 & 3,9 & 10 & 0,2 & 0,2 & 0,07 & 0,10 & 1,5 & 3,9 & 0,57 & 5,97 & 72 & 10 & 31,5 \\
\hline & $\mathrm{E}$ & $20-50$ & 166 & 29 & 172 & 633 & 4,4 & 3,9 & 9 & 0,3 & 0,2 & 0,05 & 0,06 & 0,7 & 3,0 & 0,61 & 4,31 & 53 & 14 & 7,7 \\
\hline & $\mathrm{Eg}$ & $50-65$ & 138 & 53 & 205 & 604 & 4,3 & 4,0 & 6 & 0,4 & 0,2 & 0,03 & 0,02 & 0,8 & 2,9 & 0,65 & 4,35 & 55 & 15 & 5,7 \\
\hline & $2 \mathrm{BS}$ & $65-75$ & 169 & 204 & 229 & 398 & 4,3 & 3,9 & 2 & 0,3 & 0,2 & 0,03 & 0,09 & 1,8 & 3,0 & 0,62 & 5,42 & 74 & 11 & 30,8 \\
\hline & $2 \mathrm{Cr}$ & $75-100$ & 163 & 213 & 257 & 367 & 4,4 & 4,0 & 2 & 0,4 & 0,2 & 0,02 & 0,08 & 1,6 & 2,3 & 0,70 & 4,60 & 70 & 15 & 28,5 \\
\hline Esg T3.17 & A1 & $0-15$ & 71 & 97 & 178 & 654 & 4,5 & 3,9 & 11 & 0,3 & 0,2 & 0,05 & 0,08 & 0,4 & 2,0 & 0,63 & 3,03 & 39 & 21 & 3,6 \\
\hline & Bhs & $15-30$ & 79 & 87 & 143 & 691 & 4,4 & 3,9 & 18 & 0,4 & 0,2 & 0,04 & 0,09 & 0,6 & 2,9 & 0,73 & 4,23 & 45 & 17 & 26,0 \\
\hline & $\mathrm{E}$ & $30-50$ & 74 & 66 & 158 & 702 & 4,4 & 4,0 & 5 & 0,3 & 0,2 & 0,03 & 0,05 & 0,3 & 1,3 & 0,58 & 2,18 & 34 & 27 & 6,4 \\
\hline & $\mathrm{Bh}$ & $50-60$ & 86 & 118 & 133 & 663 & 4,5 & 4,0 & 11 & 0,2 & 0,1 & 0,05 & 0,09 & 1,0 & 4,6 & 0,44 & 6,04 & 69 & 7 & 4,5 \\
\hline & $2 \mathrm{Bs}$ & $60-70$ & 185 & 196 & 187 & 432 & 4,4 & 4,0 & 7 & 0,2 & 0,1 & 0,02 & 0,07 & $\begin{array}{l}1,7 \\
1,7\end{array}$ & 5,7 & 0,39 & 7,79 & 81 & 5 & 4,1 \\
\hline & $2 \mathrm{Cr}$ & $70-100$ & 180 & 243 & 192 & 385 & 4,3 & 3,9 & 1 & 0,2 & 0,1 & 0,02 & 0,12 & 1,8 & 3,6 & 0,44 & 5,84 & 80 & 8 & 1,7 \\
\hline Esg T3.35 & A & $0-15$ & 121 & 63 & 255 & 561 & 4,1 & 3, & 38 & 0 & 0,2 & 0,0 & 0,14 & 1,1 & 7,7 & 0,63 & 9,43 & 64 & 7 & 4,8 \\
\hline & $\mathrm{E}$ & $15-27$ & 84 & 39 & 290 & 587 & 4,3 & 3,8 & 6 & 0,2 & 0,2 & 0,03 & 0,05 & 0,2 & 1,8 & 0,48 & 2,48 & 29 & 19 & 2,7 \\
\hline & $2 \mathrm{Bh}$ & $27-35$ & 143 & 55 & 274 & 528 & 4,1 & 3,7 & 25 & 0,2 & 0,2 & 0,02 & 0,02 & 2,4 & 8,2 & 0,44 & 11,04 & 85 & 4 & 4,8 \\
\hline & $3 \mathrm{Cg}$ & $35-47$ & 151 & 83 & 249 & 517 & 4,2 & 3,9 & 4 & 0,2 & 0,1 & 0,03 & 0,02 & 1,6 & 4,2 & 0,35 & 6,15 & 82 & 6 & 7,3 \\
\hline & $3 \mathrm{Bs}$ & $47-50$ & 179 & 92 & 185 & 545 & 4,2 & 3,9 & 6 & 0,2 & 0,1 & 0,02 & 0,04 & 1,3 & 5,9 & 0,36 & 7,56 & 78 & 5 & 29,0 \\
\hline & $3 \mathrm{Bh}$ & $50-82$ & 196 & 114 & 283 & 407 & 4,2 & 3,9 & 5 & 0,2 & 0,1 & 0,02 & 0,06 & 1,5 & 6,1 & 0,38 & 7,98 & 80 & 5 & 16,7 \\
\hline
\end{tabular}

Perfil = número do perfil amostrado; $\mathrm{C}=$ carbono orgânico; $\mathrm{S}=$ soma de bases; $\mathrm{m}=$ saturação por alumínio; $\mathrm{V}=$ saturação por bases; $\mathrm{Fe}=$ ferro total. Continua; ND = não determinado. 
Quadro 2. Resultados analíticos do detalhe da passagem Espodossolo Ferrocárbico (E Sg)/Gleissolo Háplico (GXbd) perfis T3.28 e T3.28A

\begin{tabular}{|c|c|c|c|c|c|c|c|c|c|c|c|c|c|c|c|c|c|c|c|c|}
\hline \multirow{2}{*}{$\begin{array}{l}\text { Solo/ } \\
\text { perfil }\end{array}$} & \multirow[b]{2}{*}{ Hor. } & \multirow[b]{2}{*}{ Prof. } & \multicolumn{4}{|c|}{ Análise granulométrica } & \multicolumn{2}{|c|}{ pH } & \multicolumn{7}{|c|}{ Complexo sortivo } & \multirow[b]{2}{*}{$\mathbf{S}$} & \multirow[b]{2}{*}{ CTC } & \multirow[b]{2}{*}{$\mathbf{m}$} & \multirow[b]{2}{*}{$\mathbf{v}$} & \multirow[b]{2}{*}{$\mathbf{F e}$} \\
\hline & & & Argila & Silte & $\begin{array}{c}\text { Areia } \\
\text { fina }\end{array}$ & $\begin{array}{c}\text { Areia } \\
\text { grossa }\end{array}$ & $\mathrm{H}_{2} \mathrm{O}$ & $\mathrm{KCl}$ & C & $\mathrm{Ca}$ & Mg & K & $\mathrm{Na}$ & Al & H & & & & & \\
\hline \multirow{9}{*}{$\begin{array}{c}\text { Esg } \\
\text { T3.28 }\end{array}$} & & $\mathrm{cm}$ & \multicolumn{4}{|c|}{$\mathrm{g} \mathrm{kg}^{-1}$} & \multicolumn{3}{|r|}{$\mathrm{gkg}^{-1}$} & \multicolumn{6}{|c|}{$-\mathrm{cmol}_{c} \mathrm{~kg}^{-1}$} & & & \multicolumn{2}{|c|}{ — $\%$} & $\mathrm{~g} \mathrm{~kg}^{-1}$ \\
\hline & Al & $0-7$ & 104 & 79 & 179 & 638 & 4,4 & 3,7 & 16 & 0,3 & 0,2 & 0,13 & 0,12 & 0,9 & 4,5 & 0,75 & 6,15 & 54,5 & 12,2 & 5,1 \\
\hline & $A / E$ & $7-20$ & 112 & 101 & 198 & 589 & 4,4 & 3,9 & 13 & 0,2 & 0,2 & 0,08 & 0,06 & 1,1 & 4,3 & 0,54 & 5,94 & 67,1 & 9,1 & 2,1 \\
\hline & $2 \mathrm{Bh}$ & $20-36$ & 110 & 83 & 216 & 591 & 4,3 & 3,9 & 15 & 0,2 & 0,1 & 0,06 & 0,05 & 0,8 & 3,8 & 0,41 & 5,01 & 66,1 & 8,18 & 5,0 \\
\hline & $2 \mathrm{E}$ & $36-59$ & 83 & 45 & 145 & 727 & 4,5 & 3,9 & 3 & 0,2 & 0,1 & 0,03 & 0,02 & 0,3 & 1,5 & 0,35 & 2,15 & 46,1 & 16,3 & 3,4 \\
\hline & 3Bhs & $59-64$ & 126 & 174 & 297 & 403 & 4,2 & 3,6 & 40 & 0,3 & 0,2 & 0,03 & 0,05 & 4,0 & 9,2 & 0,58 & 13,78 & 87,3 & 4,21 & 5,5 \\
\hline & 3Bhs2 & $64-74$ & 187 & 212 & 283 & 318 & 4,4 & 4,0 & 24 & 0,2 & 0,1 & 0,03 & 0,05 & 2,1 & 8,9 & 0,38 & 11,38 & 84,7 & 3,34 & 88,3 \\
\hline & 3Bsm & $74-77$ & 179 & 198 & 158 & 465 & 4,6 & 4,2 & 19 & 0,2 & 0,1 & 0,04 & 0,08 & 0,7 & 7,9 & 0,42 & 9,02 & 62,5 & 4,66 & 203,0 \\
\hline & $3 \mathrm{Cr}$ & $77-106$ & 124 & 143 & 346 & 387 & 4,3 & 4,0 & 1 & 0,1 & 0,1 & 0,04 & 0,03 & 0,9 & 2,7 & 0,27 & 3,87 & 76,9 & 6,98 & 3,4 \\
\hline GXbd & Al & $0-10$ & 115 & 90 & 187 & 608 & 4,3 & 3,6 & 16 & 0,2 & 0,2 & 0,09 & 0,12 & 1.2 & 4,8 & 0,61 & 6,61 & 66,3 & 9,23 & 3,2 \\
\hline \multirow[t]{5}{*}{$\mathrm{T} 3.28^{\mathrm{A}}$} & $\mathrm{Cg}$ & $10-30$ & 121 & 118 & 238 & 523 & 4,5 & 3,9 & 5 & 0,2 & 0,1 & 0,04 & 0,05 & 0,7 & 2,3 & 0,39 & 3,39 & 64,2 & 11,5 & 7,5 \\
\hline & $2 \mathrm{Cg}$ & $30-40$ & 118 & 114 & 206 & 562 & 4,3 & 3,9 & 6 & 0,2 & 0,1 & 0,03 & 0,02 & 0,6 & 2,1 & 0,35 & 3,05 & 63,2 & 11,5 & 1,5 \\
\hline & $2 \mathrm{Cg} 2$ & $40-60$ & 145 & 103 & 211 & 541 & 4,4 & 3,9 & 10 & 0,1 & 0,1 & 0,04 & 0,06 & 0,7 & 2,9 & 0,30 & 3,90 & 70,0 & 7,69 & 1,6 \\
\hline & $2 \mathrm{Cg} 3$ & $60-90$ & 143 & 96 & 223 & 538 & 4,3 & 3,9 & 4 & 0,2 & 0,1 & 0,05 & 0,02 & 0,5 & 1,9 & 0,37 & 2,77 & 57,5 & 13,36 & 16,3 \\
\hline & $3 \mathrm{Cr}$ & $90-100$ & 129 & 179 & 257 & 435 & 4,4 & 4,0 & 1 & 0,2 & 0,1 & 0,03 & 0,02 & 0,7 & 1,7 & 0,35 & 2,75 & 66,7 & 12,73 & 21,6 \\
\hline
\end{tabular}

Perfil = número do perfil amostrado; $\mathrm{C}=$ carbono orgânico; $\mathrm{S}=$ soma de bases; $\mathrm{m}$ = saturação por alumínio; $\mathrm{V}=$ saturação por bases; $\mathrm{Fe}=$ ferro total; ND = não determinado.

aos supracitados); oAl trocável é el evado eaumenta nos horizontes organominerais do Espodossolo, com óbvio aumento da saturação. Portanto, o pH baixo mais meio redutor (solos ácidos) com forte atuação do alumínio livre favorecem a mobilização e migração do ferro, que apresenta teores totais baixos, inclusive com a verificação em campo e nos dados analíticos dessa migração e concentração.

A morfologia da seqüência (Figura 4a) mostra a invasão da hidromorfia sobre os horizontes do Espodossolo (mosqueado crescentenessa direção, até gleização integral ), que se processa desigualmente, na base $\left(2 \mathrm{Cg}_{2}\right.$ sobre $2 \mathrm{Bh} / 2 \mathrm{E}$ ) e por línguas (3Cg sobre $3 \mathrm{Bhs} / 3 \mathrm{Bhs} / \mathrm{BBsm})$, desagregando a crosta de ferro e de matéria orgânica e reduzindo-as, notado nos volumes brancos, acinzentados e amarelados interpenetrando e desagregando os volumes vermel hos (ferro) epretos (matéria orgânica) através de fissuras ou zonas decontato, por baixo e por cima das crostas, como observado nos perfis T3.28 e T3.28A. Essa hidromorfia vem destruindo a camada de ortstein pelas linhas de penetração deágua, sendo as camadas ferruginosas pouco mais resistentes à desagregação do que as de matéria orgânica, testemunhado por fragmentos de ortstein, em continuidade a esses níveis endurecidos, no interior da massa gleizada. Neste caso, a matéria orgânica ácida em abundância auxilia a mobilização do ferro. Essa gl eização é pronunciada próximo aos canais de drenagem (D), sobretudo à direita (Figura 3). Nos Bh, ocorre também declínio do carbono total em direção à gl eização.

Da mesma forma, pode-se claramente observar esta interpenetração da hidromorfia nos horizontes do Espodossol o pel o exame dos perfis T3.35 eT3.35A, onde, de forma abrupta, percebe-se a passagem dos horizontes E e2Bh para Cg e2Cg (Figura 4b). Notasetambém que o avanço da hidromorfia do horizonte 3Cg sobre o 3Bh e sobre as camadas de ortstein (3Bs) deixa resquícios, isolando fragmentos de 3Bs e deixando, deforma residual, como testemunha, uma bolsa de 3Bh envolta pelo $3 \mathrm{Cg}$. I sso vem mostrar claramente o encaminhamento das transformações. As marcas verticais de penetração de matéria orgânica no $3 \mathrm{Cr}$ mostram para onde vai a matéria orgânica deslocada em cima (Figura 4b).

Assim, oEspodossol osubsistenas porções mel hor drenadas, devendo ter-se formado em condição dimática mais seca, distinta da atual, pois não ocorre em outras posições da vertente e topo, ou seja, necessitaria da oscilação de lençol e oxigenação para a precipitação e acumulação do ferro e matéria orgânica, portanto um pal eo-pedoclima. Quando a condição de umidade aumentou, tornou-se possível a formação do Gleissolo, bem como a destruição do Espodossolo (situação atual).

Além disso, várias camadas deacumulação de ferro e matéria orgânica mostram antigos e diferentes níveis de lençol da superfície para baixo, que estão sendo destruídas conforme a migração da matéria orgânica ácida, como no Perfil T3.20 (E spodossolo). Assim, definiu-se que a evolução do Gleissolo é dependenteda drenagem, enquanto a do Espodossolo depende também da disponibilidade de matéria orgânica, porosidade e sua diferenciação para migração e acúmulo (novamente, condições de umidadedistintas das atuais). É precisoassinalar que esses solos desenvolvem-se indiferentemente às variações enaturezas litológicas dos materiais (areias, seixos de diversos tamanhos e gnaisses alterados). 
Tais indícios mostram o solo em meio ácido com os vários horizontes Bh, Bhs e Bsm (Figura 4a,b) de dissociação do ferro, que anteriormente estaria ligado às argilas ou aos minerais primários, e que migraram com matéria orgânica e se acumularam nesses horizontes subsuperficiais. Essa acumulação se dá por meio da oxidação do ferro, em virtude da oscilação do lençol freático. Por outro lado, a ação biológica que age na compartimentação da matéria orgânica ocorre em meio não saturado, o que implicaria oxigenação do perfil de solo (relação textural ou estação mais seca que atual). Atualmente, essa umidade é constante, não propiciando tais condições.

Dessa forma, pode-se dizer que, nesse compartimento do planalto, os solos formaram-se em períodos que apresentavam condições climáticas distintas das que ocorrem hoje, provavel mente com menor disponibilidade de água ou ainda com estações marcadas ou mais bem definidas. Nas condições atuais, esse excesso de água acentua os processos morfogenéticos e pedogênicos e o desequilíbrio entre o perfil hídrico e o pedológico, tendendo à destruição das argilas elixiviação dos el ementos.

\section{CONCLUSÕES}

1. As observações de campo e os dados indicaram que a vegetação atual, floresta densa, favoreceu o fornecimento de matéria orgânica ácida, que tem influência na evolução dos solos. Por outro lado, o clima atual, úmi do sem estação seca, foi responsável pela pouca sincronia entre os perfis de Espodossol os e os perfis hídricos. Há um excedente hídrico, inclusiveacentuado próximo aos canais naturais de drenagem, a partir dos quais se desenvolveram os Gleissolos: estes avançam lateralmente sobre aqueles, provocando a remobilização do ferro acumulado nos horizontes dos Espodossolos, junto com a matéria orgânica. O meio ácido (matéria orgânica) e a umidade elevada foram responsáveis por essa remobilização, eo meio poroso (heterometria do material) facilitou a remoção do ferro.

2. Na associação de sol os estudada, a justaposição de Espodossol os e Gleissol os mostrou uma invasão destes sobre aqueles. Assim, os Espodossolos representam uma evolução anterior, que hojeem dia subsiste nas porções mais drenadas, ao passo que os Gleissol os representam a evol ução contemporânea. Os primeiros desenvolveram-se sob clima anterior com estação seca mais marcada e, com o aumento da umidade climática holocênica, entraram em desequilíbrio hídrico, sendo invadidos pela gl eização.

3. Dessa maneira, esses solos evidenciaram situações ambientais diversas, os E spodossol os sendo testemunhas de situações paleoclimáticas e pal eopedogenéticas diferentes das atuais.

\section{LITERATURA CITADA}

BOULET, R.; CHAUVEL, A.; HUMBEL, F.X. \& LUCAS, Y. Analyse structurale et cartographie en pédologie:I-Prise en compte del'organisation bidimensionele dela couverture pédol ogique: les études detoposéquences et leurs principaux apports à la connaissance des sols. Cah. ORSTOM, Sér. Pédol., 4:309-321, 1982a.

BOULET, R.; HUMBEL, F.X. \& LUCAS, Y. Analyse structurale et cartographie en pédologie: II-Une méthode d'analyse prenant en compte l'organisation tridimensionelle des couvertures pédologiques. Cah. ORSTOM, Sér. Pédol., 4:323-339, 1982b.

BOULET, R.; HUMBEL, F.X. \& LUCAS, Y. Analyse structurale et cartographie en pédologie: III-Passage de la phase analytique à une cartographie générale synthétique. Cah. ORSTOM, Sér. Pédol., 4:341-359, 1982c.

BOULET, R. Análise estrutural da cobertura pedológica e a experimentação agronômica. In: CONGRESSO BRASILEIRO DE CIÊNCIA DO SOLO, 21., Campinas, 1987. Resumos. Campinas, Sociedade Brasileira deCiência do Solo, 1988. p.431-446.

CAMARGO, O.A.; MONIZ, A.C.; J ORGE, J.A. \& VALADARES, J.M.A.S. Métodos de análise química, mineralógica efísica de solos do Instituto Agronômico de Campinas. Campinas, Instituto Agronômico de Campinas, 1986. 94p. (Boletim Técnico, 106)

CAMARGO, M.N.;KLANT, E. \& KAUFFMAN,J.H. Classificação de sol os usada em levantamentos no Brasil. B. Inf. SBCS, 12:11-33, 1987.

EMPRESA BRASILEIRA DE PESQUISA AGROPECUÁRIA EMBRAPA. Serviço Nacional de Levantamento e Conservação do Solo. Revisão técnica de levantamento de solos. Rio de J aneiro. 1979. 83p. (Série Miscelânea, 1)

EMPRESA BRASILEIRA DE PESQUISA AGROPECUÁRIA EMBRAPA. Centro Nacional de Pesquisa de Solos. (Rio de J aneiro, RJ ). Sistema Brasileiro de Classificação de Solos. Brasília, Produção de Informação; Rio de J aneiro, 1999. 412p.

LEMOS, R.C. \& SANTOS, R.D. Manual de descrição e coleta de solo no campo. 3 ed. Campinas, Sociedade Brasileira de Ciência do Solo, Serviço Nacional de Levantamento e Conservação de Solos, 1996. 83p.

OLIVEIRA,J.B.; ACOMINE,P.K.T. \& CAMARGO, M.N. Classes gerais de solos do Brasil: guia auxiliar para seu reconhecimento. J aboticabal, Fundação de Estudos e Pesquisas em Agronomia, Medicina Veterinária eZootecnia, 1992. 201p.

ROSSI, M. Fatores formadores da paisagem litorânea: a bacia do Guaratuba, SP - Brasil. São Paulo, Universidade de São Paulo, 1999. 162p. (Tese de Doutorado) 
